\title{
Corrigendum: Intestinal immune homeostasis is regulated by the crosstalk between epithelial cells and dendritic cells
}

Monica Rimoldi, Marcello Chieppa, Valentina Salucci, Francesca Avogadri, Angelica Sonzogni, Gianluca M Sampietro, Angelo Nespoli, Giuseppe Viale, Paola Allavena \& Maria Rescigno

Nat. Immunol. 6, 507-514 (2005); published online 10 April 2005; corrected after print 20 November 2014

In the version of this article initially published, the plots at top and middle left in Figure 5a were incorrect. The correct plots are now presented. The error has been corrected in the HTML and PDF versions of the article.

\section{Corrigendum: Direct extracellular interaction between the early secreted antigen ESAT-6 of Mycobacterium tuberculosis and TLR2 inhibits TLR signaling in macrophages}

Sushil Kumar Pathak, Sanchita Basu, Kunal Kumar Basu, Anirban Banerjee, Shresh Pathak, Asima Bhattacharyya, Tsuneyasu Kaisho, Manikuntala Kundu \& Joyoti Basu

Nat. Immunol. 8, 610-618 (2007); published online 7 May 2007; corrected after print 20 November 2014

In the version of this article initially published, lanes 1, 2 and 4 of Figure $5 \mathrm{~b}$ included duplicates. The correct immunoblot is now presented. The error has been corrected in the HTML and PDF versions of the article.

\section{Corrigendum: The RIP1-RIP3 complex initiates mitochondrial fission to fuel NLRP3}

\section{Manira Rayamajhi \& Edward A Miao}

Nat. Immunol. 15, 1100-1102 (2014); published online 14 November 2014; corrected after print 3 December 2014

In the version of this article initially published, vesicular stomatitis virus was incorrectly identified as a double-stranded RNA virus. It should be identified as a single-stranded RNA virus throughout (and 'dsRNA' should be 'RNA' throughout the second paragraph and in the first sentence of the sixth paragraph and the seventh sentence of the seventh paragraph, and 'dsDNA' should be 'DNA' throughout). Also, the end of the second sentence of the second paragraph is incorrect. It should read as follows: “...the Toll-like receptor TLR9 detects DNA viruses, and TLR3 and TLR9 detect RNA viruses." These errors have been corrected in the HTML and PDF versions of the article. 